\title{
The application of non-cross-linked polystyrene-supported triphenylarsine in Stille coupling reactions
}

\author{
Kelvin Chi Yin Lau and Pauline Chiu* \\ Department of Chemistry and Open Laboratory of Chemical Biology, Institute of Molecular Technology for Drug \\ Discovery and Synthesis, The University of Hong Kong, Pokfulam Road, Hong Kong, PR China \\ Received 5 December 2006; revised 2 January 2007; accepted 4 January 2007
}

10 Abstract-NCPS- $\mathrm{AsPh}_{3}$ is a soluble polymer-supported triphenylarsine that performed equally well compared to free triphenylarsine as ligands in the Stille cross-coupling reaction of organic electrophiles and organostannanes, with the advantage that it can be conveniently and efficiently separated from the reaction by precipitation, and recycled for further use. The performance of this noncross-linked polystyrene-supported arsine was found to be generally superior in Stille coupling reactions over the analogous polymer-supported phosphine, paralleling observations on the free ligands. Palladium-catalyzed modification of the polymer-supported arsine was possible through $\mathrm{Pd}-\mathrm{Ar} / \mathrm{As}-\mathrm{Ph}$ exchange. Exploiting the ease of isolation of the polymer-supported reagent, the modified arsine is recycled for reuse in the Stille reaction and has led to a reduction in the yield of undesired scrambling products.

(C) 2007 Published by Elsevier Ltd.

Triphenylarsine has synthetic applications in the gener-

20 ation of arsonium salts and highly nucleophilic ylides, ${ }^{1}$ as an effective ligand in various palladium-catalyzed carbon-carbon bond forming reactions, ${ }^{2}$ and as an epoxidation agent ${ }^{3}$ and a mediator for converting isocyanates to carbodiimides in its oxide form. ${ }^{4}$ Due to the rather inhibitive toxicity of arsenic reagents, we thought it desirable to examine the immobilization of triphenylarsine on polymer support that would provide an alternative reagent for arsine-mediated reactions, but would also be conveniently separated to simplify

30 reaction workup and purification, exploiting the advantages of supported reagents in organic synthesis. ${ }^{5}$ The potentially convenient recovery of immobilized triphenylarsine would facilitate re-use and would allow arsine-mediated reactions to be conducted in a more 'green' manner. Thus, we have recently synthesized cross-linked and non-cross-linked polystyrene-supported triphenylarsine reagents. ${ }^{6}$ Their utility in Suzuki cross-coupling reactions, aryl halide homocoupling and alkene epoxidations have been demonstrated. ${ }^{6,7}$

40 Herein we evaluate non-cross-linked triphenylarsine (1) in the Stille reaction, which accomplishes the cross-cou-

\footnotetext{
* Corresponding author. Tel.: +852 2859 8949; fax: +852 2857 1586; e-mail: pchiu@hku.hk
}

pling between organic electrophiles and organostannanes, and is one of the classic palladium-catalyzed carbon-carbon bond forming reactions in the organic chemist's repertoire. ${ }^{8}$ The studies by Farina and coworkers have shown that triphenylarsine was a superior ligand to triphenylphosphine in improving the yield, reactivity and turnover rates in Stille reactions. ${ }^{4}$ Triphenylarsine promotes the rate-determining transmetallation step and can induce a rate increase in the Stille reaction by a factor of over $1000 .^{2}$ In this Letter, we demonstrate the applicability of the triphenylarsine immobilized on non-cross-linked polystyrene (NCPS) in Stille coupling reactions, and the modification of the immobilized triphenylarsine by palladium-catalyzed $\mathrm{Pd}-\mathrm{Ar} / \mathrm{As}-\mathrm{Ph}$ exchange to enhance the yields of the desired cross-coupling products.

Using $10 \%$ NCPS- $\mathrm{AsPh}_{3}(\mathbf{1})$ as the ligand, ${ }^{9}$ various Stille coupling reactions of aryl halides and triflates were examined and the results are shown in Table 1. The Stille reaction using free triphenylarsine as the ligand for palladium compared to the reaction using $\mathbf{1}$ as the ligand were found to occur at the same rates to give similarly excellent yields of product (Table 1, entries 1 and 2). The non-cross-linked polystyrene support of $\mathbf{1}$ is a soluble polymer and this provided solution-phaselike conditions for the reaction. Similar reaction rates using the free triphenylarsine and $\mathbf{1}$ had been observed also in the Suzuki coupling reactions. ${ }^{6}$ 
Table 1. Stille coupling reactions with organostannanes

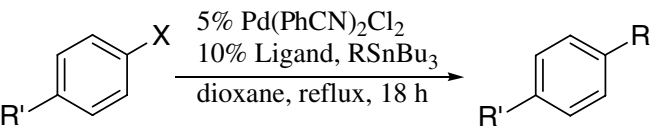

\begin{tabular}{clllll}
\hline Entry & $\mathrm{R}$ & $\mathrm{X}$ & $\mathrm{R}^{\prime}$ & Ligand $^{\mathrm{a}}$ & Yield $^{\mathrm{b}}(\%)$ \\
\hline 1 & $\mathrm{Ph}$ & $\mathrm{Br}$ & $\mathrm{H}$ & $\mathrm{AsPh}_{3}$ & $88(83)^{\mathrm{c}}$ \\
2 & $\mathrm{Ph}$ & $\mathrm{Br}$ & $\mathrm{H}$ & $\mathbf{1}$ & $95(81)^{\mathrm{c}}$ \\
3 & $\mathrm{Ph}$ & $\mathrm{Br}$ & $\mathrm{CHO}$ & $\mathbf{1}$ & $(82)$ \\
4 & $\mathrm{Ph}$ & $\mathrm{Br}$ & $\mathrm{OMe}$ & $\mathbf{1}$ & 69 \\
5 & $\mathrm{Ph}$ & $\mathrm{Br}$ & $\mathrm{Cl}$ & $\mathbf{1}$ & 72 \\
6 & $\mathrm{Ph}$ & $\mathrm{Br}$ & $\mathrm{Ph}$ & $\mathbf{1}$ & 74 \\
7 & $\mathrm{Ph}$ & $\mathrm{I}$ & $\mathrm{H}$ & $\mathbf{1}$ & $72(61)$ \\
8 & $\mathrm{Ph}$ & $\mathrm{OTf}$ & $\mathrm{H}$ & $\mathbf{1}$ & $91^{\mathrm{d}}$ \\
9 & $\mathrm{Vinyl}$ & $\mathrm{Br}$ & $\mathrm{Cl}$ & $\mathbf{1}$ & $87^{\mathrm{e}}$ \\
10 & $\mathrm{Vinyl}$ & $\mathrm{I}$ & $\mathrm{Cl}$ & $\mathbf{1}$ & $93^{\mathrm{e}}$ \\
11 & $\mathrm{Vinyl}$ & $\mathrm{Br}$ & $\mathrm{Ph}$ & $\mathbf{1}$ & $(86)^{\mathrm{e}}$ \\
12 & $\mathrm{Ph}$ & $\mathrm{Br}$ & $\mathrm{Cl}$ & $\mathbf{2}$ & 61 \\
13 & $\mathrm{Ph}$ & $\mathrm{Br}$ & $\mathrm{Ph}$ & $\mathbf{2}$ & 67 \\
14 & $\mathrm{Ph}$ & $\mathrm{I}$ & $\mathrm{H}$ & $\mathbf{2}$ & 33 \\
15 & $\mathrm{Ph}$ & $\mathrm{OTf}$ & $\mathrm{H}$ & $\mathbf{2}$ & $99^{\mathrm{d}}$ \\
\hline
\end{tabular}

${ }^{\mathrm{a}} \mathrm{NCPS}-\mathrm{AsPh}_{3}(\mathbf{1}) ; \mathrm{NCPS}-\mathrm{PPh}_{3}(2)$.

${ }^{\mathrm{b}}$ Yields determined by GC; yields in brackets are isolated yields.

${ }^{\mathrm{c}}$ Reaction time was $5 \mathrm{~h}$.

${ }^{\mathrm{d}} 2.5 \% \mathrm{Pd}_{2}(\mathrm{dba})_{3}, 100^{\circ} \mathrm{C}$, NMP.

${ }^{\mathrm{e}} 2.5 \% \mathrm{Pd}_{2}(\mathrm{dba})_{3}, 80^{\circ} \mathrm{C}$, NMP.

70 The effectiveness of $\mathbf{1}$ as a ligand was surveyed for various Stille reactions of electron-rich and electron-deficient substrates, aryl halides and triflates (Table 1, entries 3-8). All reactions occurred under typical reaction conditions as expected. The Stille coupling of vinyltributylstannane proceeded with excellent yields (Table 1, entries 9-11). In each case, removal of the arsine was done by precipitation. The product mixture was concentrated and redissolved in a minimum amount of hot THF, then added to $20 \%$ ether in hexane to precip-

80 itate $\mathbf{1}$. Compound $\mathbf{1}$ can then be isolated by suction filtration, with a recovery of about $90-95 \%$. The rest of the product mixture was washed with saturated aqueous KF before GC analysis and/or purification by column chromatography.

Comparison was also made with NCPS- $\mathrm{PPh}_{3}$ reagent (2) as a ligand for Stille reactions (Table 1, entries 12-15). The observations by Farina and co-workers that the arsine ligand was generally superior was confirmed for the soluble polymer-supported reagents as well. ${ }^{2}$

90 In Stille arylation reactions using phenyltributylstannane, biphenyl was consistently found as a side product. Biphenyl could result from two other reactions. One was the homocoupling of $\mathrm{PhSnBu}_{3}$ itself. ${ }^{2 \mathrm{c}, 10}$ Another was the Stille reaction after the exchange of aryl groups between ligand $\mathbf{1}$ and the aryl halide. Segelstein et al. have reported that, especially in Stille coupling reactions involving less reactive, electron-rich substrates, phenyl groups on $\mathrm{Ph}_{3} \mathrm{P}$ exchange with the electron-rich aryl group of the organopalladium intermediate, and then

100 proceeded to couple with the organostannane to generate biphenyl, and result in a lower yield of the desired cross-coupling product. $^{11}$ Such scrambled coupling products have been obtained in palladium-catalyzed reactions in yields varying from $4 \%$ to $58 \%$.

This $\mathrm{Pd}$-aryl/P-aryl exchange process has been productively exploited by Chan and co-workers to synthesize functionalized arylphosphines ${ }^{12}$ and arylarsines. ${ }^{13}$ The exchange reactions resulted in $25-68 \%$ yields of the functionalized phosphines or arsines, which were isolated from an excess of $\mathrm{Ph}_{3} \mathrm{P}$ or $\mathrm{Ph}_{3}$ As typically by conventional column chromatography.

In the Stille reactions using $\mathbf{1}$ as a ligand, the Pd-aryl/ P-aryl exchange would result in a modification in the structure of the polymer-supported arsine. If this new reagent $\mathbf{1}^{\prime}$ could be successfully recycled and reemployed in Stille reactions involving the same aryl halide, the scrambling process should have a diminished effect on the yield of the desired coupling product, since the cross-coupling product and the scrambled product would effectively be the same. Alternatively, pretreating $\mathbf{1}$ with an aryl halide in the presence of palladium should also lead to a similar modification of the arsine polymer (Eq. 1). This pretreatment could serve as a way to 'prime' 1 to promote the formation of the desired hetero-coupling product. Without resorting to conventional isolation techniques such as chromatography, by taking advantage of the ease of recovery of the polymer-supported arsine, we demonstrate the exploitation of this scrambling process to modify $\mathbf{1}$ to $\mathbf{1}^{\prime}$.

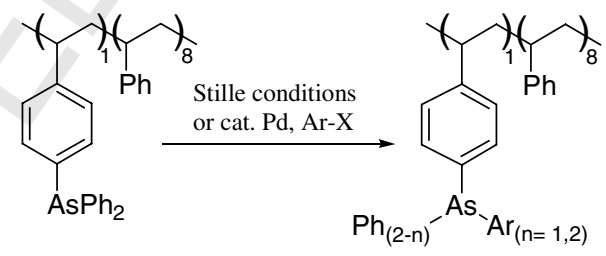

To examine the efficiency and effect of recycling $\mathbf{1}$, the Stille reaction using 4-bromoanisole as an electron-rich aryl halide substrate was carried out using a higherthan-usual loading of $\mathbf{1}$ ( $20 \mathrm{~mol} \%)$, for the purpose of observing a more pronounced effect of scrambling. When fresh 1 was used as a ligand in the first run, only a $43 \%$ yield of $p$-methoxybiphenyl was obtained, together with $37 \%$ of the biphenyl side product (Table 2 , cycle 1). The subsequent reaction using recycled 1 resulted in an increase in the yield of 4-methoxybiphenyl with a concomitant decrease in the yield of biphenyl of about $20 \%$, clearly demonstrating that the use of recycled 1 enhanced the yield of the cross-coupling product (Table 2, cycle 2). The yields of both products did not further increase or decrease in subsequent cycles 3-5. The $15-20 \%$ yield of biphenyl that was still produced in the reactions using recycled $\mathbf{1}$ is attributed to the homocoupling of tributylphenyltin. This was quantified by experiment, where a $16 \%$ yield of biphenyl was obtained under the Stille conditions without the addition of any aryl bromide.

A second set of recycling experiments examined the Stille reaction of 4-bromochlorobenzene (Table 3). A yield enhancement of about $10 \%$ was observed using 
Table 2. Recycling of $\mathbf{1}$ in the Stille reaction of 4-bromoanisole

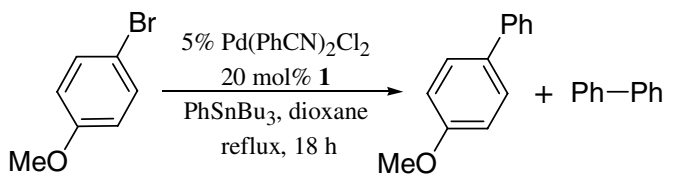

\begin{tabular}{lll}
\hline Cycle & ${\text { Yield (4-MeO-biphenyl })^{\mathrm{a}}(\%)}{\text { Yield }(\mathrm{Ph}-\mathrm{Ph})^{\mathrm{a}}(\%)}$ \\
\hline 1 & 43 & 37 \\
2 & 62 & 20 \\
3 & 70 & 20 \\
4 & 67 & 15 \\
5 & 61 & 19 \\
\hline
\end{tabular}

${ }^{\mathrm{a}} \mathrm{GC}$ yield.

Table 3. Recycling of $\mathbf{1}$ in the Stille reaction of 4-bromochlorobenzene

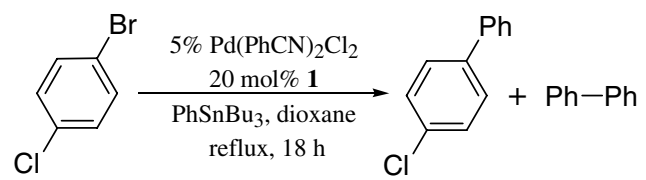

\begin{tabular}{lll}
\hline Cycle & Yield (4-Cl-biphenyl) $)^{\mathrm{a}}(\%)$ & Yield $(\mathrm{Ph}-\mathrm{Ph})^{\mathrm{a}}(\%)$ \\
\hline 1 & 69 & 34 \\
2 & 80 & 16 \\
\hline
\end{tabular}

${ }^{\mathrm{a}} \mathrm{GC}$ yield.

the recycled $\mathbf{1}$ compared to fresh $\mathbf{1}$, with a concomitant reduction in the yield of biphenyl.

Finally, 1 was treated with 4-bromoanisole in the pres160 ence of $\mathrm{Pd}_{2}(\mathrm{dba})_{3}$ to produce $\mathbf{1}^{\prime}$ which was isolated (Eq. 2). The ${ }^{1} \mathrm{H}$ NMR spectrum of $\mathbf{1}^{\prime}$ clearly shows a modified polymer-supported arsine with the incorporation of the methoxybenzene group, indicated by the appearance of a broad peak at $\delta 3.62-3.92 \mathrm{ppm}$, which is different from the sharp methoxy singlet signal of 4bromoanisole at $3.78 \mathrm{ppm}$. The broadness of this methoxy signal is indicative of incorporation into a polymeric structure.

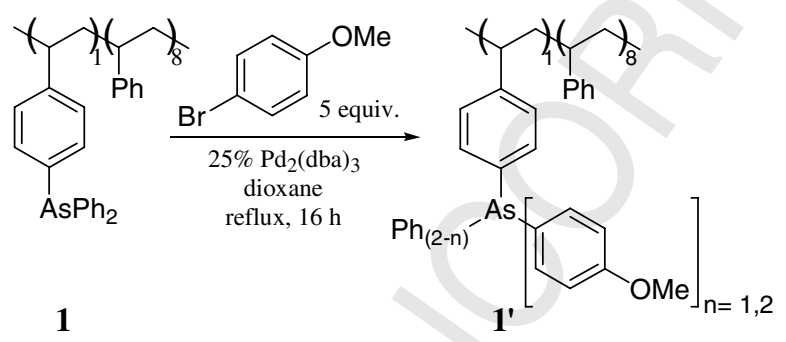

170

When $\mathbf{1}^{\prime}$ thus obtained was used as the ligand in the Stille reaction, a $17 \%$ increase in the yield of methoxybiphenyl and a corresponding 19\% reduction in the yield of biphenyl was observed compared to the same reaction using fresh 1 (Table 4).

In summary, we have demonstrated the general applicability of triphenylarsine immobilized on non-crosslinked polystyrene (1) as a recyclable ligand in Stille cou180 pling reactions. Triphenylarsine in this form could be
Table 4. Stille reaction using $\mathbf{1}$ and $\mathbf{1}^{\prime}$

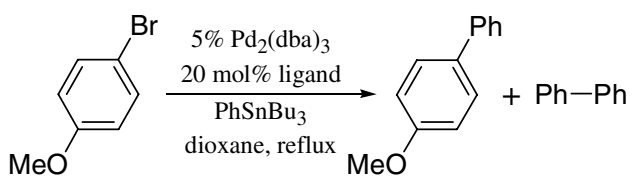

\begin{tabular}{|c|c|c|}
\hline Ligand & Yield (4-MeO-biphenyl) & Yield $(\mathrm{Ph}-\mathrm{Ph})^{\mathrm{a}}(\%)$ \\
\hline 1 & 64 & 34 \\
\hline $\mathbf{1}^{\prime}$ & 81 & 15 \\
\hline
\end{tabular}

conveniently separated and purified by concentration and precipitation. The $\mathrm{Pd}$-aryl/P-aryl exchange reaction could be exploited to synthesize a modified polymersupported arsine $\mathbf{1}^{\prime}$ that could be similarly isolated, purified and characterized or recycled in subsequent Stille reactions to significantly improve the yield of the desired cross-coupling product.

\section{Acknowledgements}

This research was supported by the University of Hong Kong, the Research Grants Council of Hong Kong SAR (HKU 7017/04 P), and the Areas of Excellence Scheme established under the University Grants Committee of the Hong Kong Special Administrative Region, China (Project No. AoE/P-10/01). K.C.Y.L. thanks the CRCG for a conference grant. We also thank Professor P. H. Toy, University of Hong Kong for his gifts of $\mathbf{1}$ and $\mathbf{2}$.

\section{Supplementary data}

All products are known compounds. The detailed experimental procedures, and ${ }^{1} \mathrm{H}$ NMR spectrum of $\mathbf{1}^{\prime}$ are available free of charge via the Internet. Supplementary data associated with this article can be found, in the online version, at doi:10.1016/j.tetlet.2007.01.005.

\section{References and notes}

1. (a) Lloyd, D.; Gosney, I.; Ormiston, R. A. Chem. Soc. Rev. 1987, 16, 45-74; (b) He, H. S.; Chung, C. W. Y.; But, T. Y. S.; Toy, P. H. Tetrahedron 2005, 61, 1385-1405; (c) Goddard, J.; Lixon, P.; Le Gall, T.; Mioskowski, C. J. Am. Chem. Soc. 2003, 125, 9242-9243; (d) Dai, W. M.; Wu, J.; Huang, X. Tetrahedron: Asymmetry 1997, 8, 19791982.

2. (a) Farina, V.; Krishnan, B. J. Am. Chem. Soc. 1991, 113, 9585-9595; (b) Faust, R.; Göbelt, B. J. Prakt. Chem. 1998, 340, 90-93; (c) Farina, V.; Krishnan, B.; Marshall, D. R.; Roth, G. P. J. Org. Chem. 1993, 58, 5434-5444.

3. van Vliet, M. C. A.; Arends, I. W. C. E.; Sheldon, R. A. Tetrahedron Lett. 1999, 40, 5239-5242.

4. (a) Monagle, J. J. J. Org. Chem. 1962, 27, 3851-3855; (b) Smith, C. P.; Temme, G. H. J. Org. Chem. 1983, 48, 46814685.

5. (a) Kirschning, A.; Monenschein, H.; Wittenberg, R. Angew. Chem., Int. Ed. 2001, 40, 650-679; (b) Bhalay, G.;
190

Please cite this article in press as: Lau, K. C. Y.; Chiu, P., Tetrahedron Lett. (2007), doi:10.1016/j.tetlet.2007.01.005 
Dunstan, A.; Glen, A. Synlett 2000, 1846-1859; (c) Toy, P. H.; Shi, M. Tetrahedron 2005, 61, 12025.

6. Lau, K. C. Y.; He, H. S.; Chiu, P.; Toy, P. H. J. Comb. Chem. 2004, 6, 955-960.

7. He, H. S.; Zhang, C.; Ng, C. K. W.; Toy, P. H. Tetrahedron 2005, 61, 12053-12057.

8. (a) Farina, V.; Krishnamurthy, V. Org. React. 1997, 50, $1-$ 676; (b) Nicolaou, K. C.; Bulger, P. G.; Sarlah, D. Angew. Chem., Int. Ed. 2005, 44, 4442-4489; (c) Espinet, P.; Echavarren, A. M. Angew. Chem., Int. Ed. 2004, 43, 47044734.

9. The NCPS-AsPh 3 polymer (1) used was determined to have a loading of $0.79 \mathrm{mmol} \mathrm{AsPh}_{3} / \mathrm{g}$ as determined by oxidation, ${ }^{3}$ which is close to the theoretical value of $0.83 \mathrm{mmol} \mathrm{AsPh}_{3} / \mathrm{g}$. 3,6

10. Kang, S. K.; Namkoong, E. Y.; Yamaguchi, T. Synth. Commun. 1997, 27, 641-646.

11. Segelstein, B. E.; Butler, T. W.; Chenard, B. L. J. Org. Chem. 1995, 60, 12-13.

12. (a) Kwong, F. Y.; Lai, C. W.; Yu, M.; Tian, Y.; Chan, K. S. Tetrahedron 2003, 59, 10295-10305; (b) Kwong, F. Y.; Lai, C. W.; Yu, M.; Chan, K. S. Tetrahedron 2004, 60, 5635-5645; (c) Wang, Y.; Lai, C. W.; Kwong, F. Y.; Jia, W.; Chan, K. S. Tetrahedron 2004, 60, 9433-9439.

13. Kwong, F. Y.; Lai, C. W.; Chan, K. S. J. Am. Chem. Soc. 2001, 123, 8864-8865. 